\title{
Development of a low-cost cement free polymer concrete using industrial by-products and dune sand
}

\author{
Najif Ismail ${ }^{1, *}$, Moustafa Mansour ${ }^{1}$, and Hilal El-Hassan ${ }^{1}$ \\ ${ }^{1}$ Department of Civil and Environmental Engineering, United Arab Emirates University, PO Box \\ 15551, Al Ain, United Arab Emirates
}

\begin{abstract}
Alkali-activated polymer concrete (APC) can potentially reduce $\mathrm{CO}_{2}$ emissions associated to concrete production by $84 \%$. The binder in APC herein was synthesized using a combined sodium silicate-sodium hydroxide solution (i.e., alkali activator), alumino-silicate rich precursor (fly ash) and slag. Light weight expanded clay and desert dune sand were used as aggregates. An overview of an experimental program was presented, which involved evaluation of fresh and mechanical properties of the produced APC and counterpart mortar (APM). Variables investigated were the fly ash to slag ratio and curing conditions. The curing regimes adopted herein included 24 hours of curing at ambient conditions, $30 \mathrm{oC}$, and $60^{\circ} \mathrm{C}$. The experimental program was undertaken in two stages, of these the first stage involved physical and chemical testing of constituent materials and the second stage involved testing or produced APM/APC. Reported were the setting times, workability, compression strength, strength development, flexural strength, tensile splitting strength, and plastic shrinkage strains. Relationship between strength results were investigated and effectiveness of codified predictive equations was evaluated.
\end{abstract}

\section{Introduction}

Global demand for cement and concrete has risen noticeably over the past few decades, driven by increasing urbanisation that reflects continuing growth in construction activity across the globe. Incidentally, cement is produced using an energy intensive process, with each ton of cement production emitting almost equal amount of carbon dioxide $\left(\mathrm{CO}_{2}\right)$ to the atmosphere [1]. To this end, substantial efforts have been invested over the past few decades to find an alternate for cement in concrete.

Alkali-activated polymer concrete (APC) is deemed a possible strategy to reduce these $\mathrm{CO}_{2}$ emissions and to put abundant industrial waste to good use, which would otherwise be accumulating in landfills and polluting the environment. APC can be produced using minerals rich in alumino-silicate (e.g. metakaoline, clay, etc.) or industrial by-products such as fly ash and blast furnace slag. The increasing cement usage rates in developing countries

\footnotetext{
${ }^{*}$ Corresponding author: najif@,uaeu.ac.ae
} 
and the Gulf region, supports furtherance in research associated to APC. This being the motivation to undertake this study, an experimental program was undertaken. The produced APC mixtures are appropriate for construction of façade wall panels and masonry blocks, which could reduce seismic mass of structure and offer superior thermal performance when introduced in building envelope.

APC is synthesised from a source material in the presence of a strong alkali activator solution. The key characteristic desired of a source material is the presence of a high percentage of alumina and silica. A blend of two very common and abundant industrial byproducts were used as source materials in this study, which were pulverized fly ash and ground granulated blast-furnace slag (referred to slag hereafter). Past research has shown that a combination of sodium hydroxide $(\mathrm{NaOH})$ and sodium silicate $\left(\mathrm{Na}_{2} \mathrm{SiO}_{3}\right)$ performs the best, where the addition of $\mathrm{Na}_{2} \mathrm{SiO}_{3}$ in alkali increases the rate of hardening [2].

APC mix design requires consideration of several variables, which include alkali-tosource material ratio, the type and concentration of alkali, $\mathrm{NaOH}$-to- $\mathrm{Na}_{2} \mathrm{SiO}_{3}$ ratio, silica-toalumina ratio, alkali oxide-to-silica ratio, and water-to-alkali oxide ratio. Amongst others are the water quantity, proportion of binder and aggregates, resting period, curing temperature, and curing time $[3,4]$. Figure 1 shows a synopsis of APC mixture variables reported in literature.

\section{Material properties}

Results of unit weight testing and XRF analysis are given in Table 1. Sieve analysis was performed on dune sand (DS), river sand, and expanded clay aggregate (ECA) in accordance with ASTM C136 [5]. The chemical composition of fly ash, slag, and dune sand was determined by performing XRF analysis. The fly ash used herein was characterised as low calcium class F as per ASTM C168 [6]. Oven-dried bulk densities/unit weights of all dry constituent materials were determined using ASTM C29 [7].

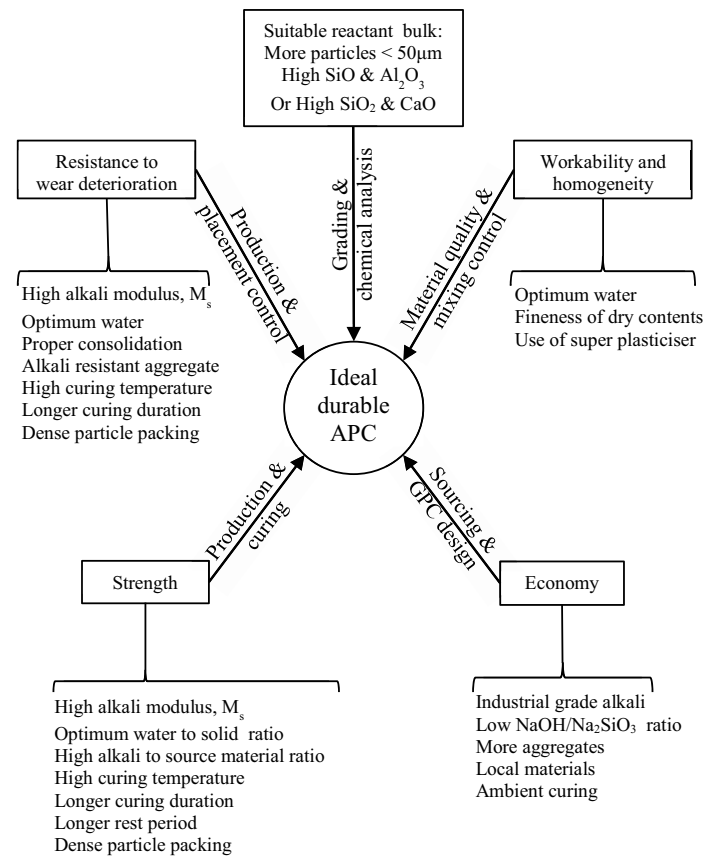

Fig. 1. Factors affecting the fresh and mechanical properties of APC. 
Figure $2 \mathrm{a}$ and $2 \mathrm{~b}$ show the particle size distribution and photos of as-received constituent materials. The as-received fly ash and slag powders were also subjected to X-ray diffraction (XRD) analysis with a $\mathrm{Cu}-\mathrm{K} \alpha$ radiation at room temperature. The powder specimens were scanned at $2 \theta$ between $10^{\circ}$ and $80^{\circ}$, with each step being $0.02^{\circ}$ and 0.5 seconds. The experimentally obtained XRD patterns are presented in Figure 3. The diffraction spectrum for fly ash showed presence of amorphous phases at $18-38^{\circ}(2 \theta)$, whereas Quartz, Mullite and Hematite were the main crystalline phases identified. The XRD pattern for slag was typical of a vitreous material, with a large halo located between $25^{\circ}$ and $35^{\circ}(2 \theta)$. The lower intensity diffraction lines were attributed to Gehlenite.

The alkali-activator solution used to synthesise APM/APC in the current study was prepared by mixing industrial grade $\mathrm{Na}_{2} \mathrm{SiO}_{3}$ solution and $18 \mathrm{M}$ concentration $\mathrm{NaOH}$ solution. A pre-weighed mass $(40 \times 18=576 \mathrm{~g})$ of $98 \%$ pure $\mathrm{NaOH}$ flakes was dissolved in distilled (de-ionised) water to prepare an $18 \mathrm{M}$ solution. The $\mathrm{Na}_{2} \mathrm{SiO}_{3}$ solution was purchased locally that had a concentration of $37.5 \%$ and a modulus of 3.2. The two solutions were combined with a fixed mass ratio of 1:1.5 $\left(\mathrm{NaOH}: \mathrm{Na}_{2} \mathrm{SiO}_{3}\right)$ to yield an alkali-activator solution with a solution modulus $\left(\mathrm{M}_{\mathrm{s}}\right.$, molar $\mathrm{SiO}_{2} / \mathrm{Na}_{2} \mathrm{O}$ ratio) of 1 .

Table 1. Chemical composition of constituent materials determined using XRF analysis.

\begin{tabular}{|c|c|c|c|c|c|c|c|}
\hline Constituent & $\begin{array}{c}\text { Density } \\
\left(\mathbf{k g} / \mathbf{m}^{\mathbf{3}}\right)\end{array}$ & $\begin{array}{c}\mathbf{S i O}_{\mathbf{2}} \\
\mathbf{\%}\end{array}$ & $\begin{array}{c}\mathbf{A l}_{\mathbf{2}} \mathbf{O}_{\mathbf{3}} \\
\mathbf{\%}\end{array}$ & $\begin{array}{c}\mathbf{F e}_{\mathbf{2}} \mathbf{O}_{\mathbf{3}} \\
\mathbf{\%}\end{array}$ & $\begin{array}{c}\mathbf{C a O} \\
\mathbf{\%}\end{array}$ & $\begin{array}{c}\mathbf{M g O} \\
\mathbf{\%}\end{array}$ & $\begin{array}{c}\text { LOI } \\
\mathbf{\%}\end{array}$ \\
\hline Fly ash & 1262 & 48.04 & 23.14 & 12.46 & 3.25 & 1.53 & 1.07 \\
\hline Slag & 1236 & 34.70 & 14.38 & 0.80 & 41.95 & 6.85 & 1.08 \\
\hline Dune Sand & 1693 & 64.94 & 3.01 & 0.71 & 14.07 & 1.28 & 0.52 \\
\hline
\end{tabular}

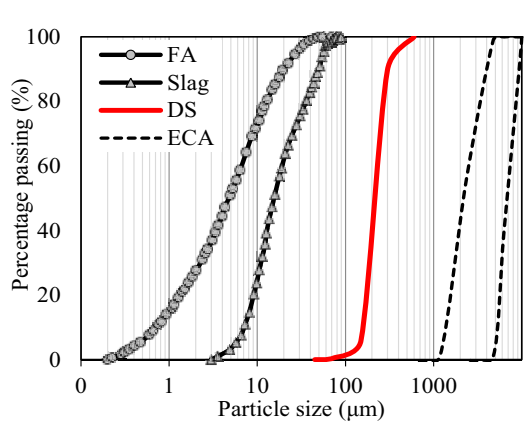

(a). Grading curves

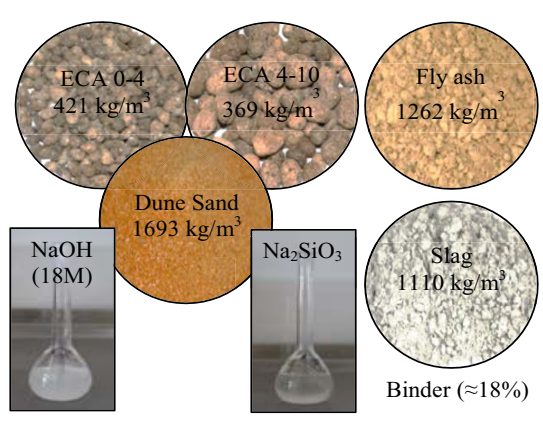

(b). Photos and densities

Fig. 2. APC constituent materials.

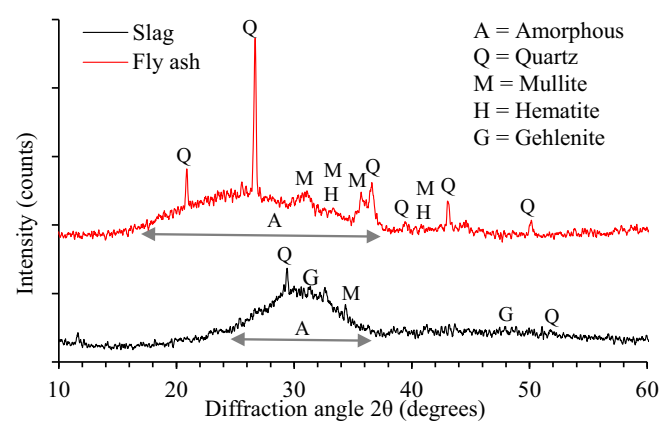

Fig. 3. XRD results for fly ash and slag. 
Table 2. Alkali-activated polymer mortar (APM) and concrete (APC) mixture proportions.

\begin{tabular}{|c|c|c|c|c|c|c|c|}
\hline Material & \multirow{2}{*}{$\begin{array}{c}\text { Density } \\
\left(\mathbf{k g} / \mathbf{m}^{\mathbf{3}}\right)\end{array}$} & \multicolumn{2}{c|}{ Constituent (kg) per batch of APM } & \multicolumn{3}{c|}{ Constituent (kg) per batch of APC } \\
\cline { 3 - 8 } & $\mathbf{A P M 1}$ & $\mathbf{A P M 2}$ & $\mathbf{A P M 3}$ & APC1 & APC2 & APC3 \\
\hline Fly ash (1) & 1262 & 433 & 325 & 216 & 302 & 227 & 151 \\
\hline Slag (2) & 1236 & - & 95 & 190 & - & 74 & 148 \\
\hline Dune sand & 1693 & 900 & 900 & 900 & 628 & 628 & 628 \\
\hline $\mathrm{ECA}^{*}$ & 494 & - & - & - & 364 & 364 & 364 \\
\hline $\mathrm{NaOH}^{n}$ & 1589 & 70 & 70 & 70 & 48 & 48 & 48 \\
\hline $\mathrm{Na}_{2} \mathrm{SiO}$ & 1392 & 104 & 104 & 104 & 73 & 73 & 73 \\
\hline Water (3) & 1000 & - & - & 41 & - & 10 & 20 \\
\hline W/SM & - & 0.21 & 0.23 & 0.25 & 0.21 & 0.23 & 0.25 \\
\hline
\end{tabular}

Where: $\mathrm{ECA}=$ expanded clay aggregate; $\mathrm{SM}=$ total mass of source material $(1+2)$; and $\mathrm{W}=$ total water (water in alkali solution +3$)$. * combined mass of the two grades of ECA

\section{Experimental program}

A testing program was undertaken to develop a suitable APC for use in building construction. The mixture proportions adopted to prepare test specimens in this study are given in Table 2 . Three different mixture designs were used, with each of these mixtures varying in fly ash-toslag $(\mathrm{F} / \mathrm{S})$ ratio with a fixed alkali-to-source material mass ratio of 0.4 . The $\mathrm{F} / \mathrm{S}$ ratios of $100 / 0,75 / 25$, and $50 / 50$ were used in mixes 1 to 3 . Test specimens were left for one day to rest at $22^{\circ} \mathrm{C}$ inside the laboratory and were then cured in ambient conditions, $30^{\circ} \mathrm{C}$, and $60^{\circ} \mathrm{C}$.

\subsection{Testing procedures}

Figure 4 shows photos of testing setups used. Initial and final setting times of each APM batch were measured using a Vicat needle apparatus at a temperature of $22^{\circ} \mathrm{C}$ in accordance with ASTM C191 [8], and slump was measured in accordance with ASTM C143 [9]. From each test set, 27 APM cubes $(50 \times 50 \times 50 \mathrm{~mm} 3)$ were tested for compression strength in accordance with ASTM C109 [10] after 3, 7 and 28 days, in sets of three.

Sets of three replicate APC cylinders $\left(100 \times 200 \mathrm{~mm}^{2}\right)$ from each test set were tested the ages of 3, 7, and 28 days for compression strength in accordance with ASTM C39 [11] and for 28-days split tensile strength using standard test procedure detailed in ASTM C496 [12]. Three APC prisms $\left(100 \times 100 \times 500 \mathrm{~mm}^{3}\right)$ from each test set were tested for 28 -days flexural strength in accordance with ASTM C78 [13]. Shrinkage strains on ambient cured APC specimens were monitored in accordance with ASTM C175 [14] using $75 \times 75 \times 300 \mathrm{~mm}^{3}$ prisms.

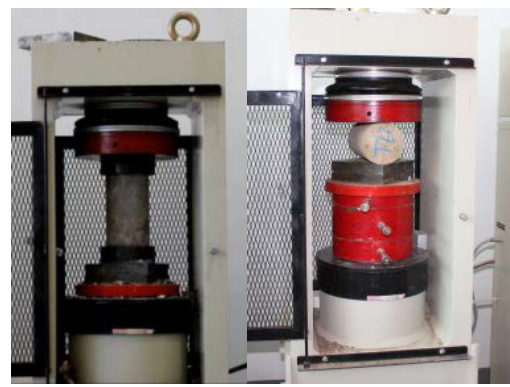

(a). $\mathrm{f}^{\prime} \mathrm{c}$

(b). $f_{\mathrm{ct}}$

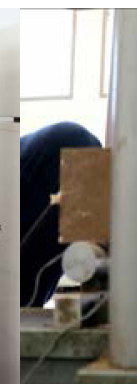

$3=$

Fig. 4. Photos of APC testing setups. 


\section{Experimental results and discussion}

\subsection{Slump and setting times}

Slump values for mixes APC1-3 were 248, 241, and $156 \mathrm{~mm}$ respectively. The initial setting time ranged between 19-31 minutes and final setting time ranged between 89-117 minutes. Preliminary tests showed that slag addition increased water demand due to water consumed in the hydration of free lime and the APC mixtures became dry. Accordingly, extra water was added to mixture APC2 and APC3. Furthermore, all mixes started to set within 10-15 minutes after mixing when the APC was produced at an ambient temperature of about $40^{\circ} \mathrm{C}$ in summer. Generally, the addition of slag to the mixture reduced the workability and accelerated hardening.

\subsection{Compression behaviour}

Peak recorded compression stress during testing of APM cubes and APC cylinders after 7 and 28 days were determined and reported as compression strength (see Figure 5a and 5b). The APM compressive strength $\left(\mathrm{f}^{\prime}{ }_{\mathrm{j}}\right)$ increased as the curing temperature was increased, with specimens cured at $60^{\circ} \mathrm{C}$ exhibiting the highest strength, which evidenced occurrence of polymerization with a higher degree. Of all the APM mixtures, APM2 $(\mathrm{F} / \mathrm{S}=75 / 25)$ was the strongest, with specimens cured at $60^{\circ} \mathrm{C}$ exhibiting $\mathrm{f}^{\prime}{ }_{\mathrm{j}}$ of $78.2 \mathrm{MPa}$ after 7 days and 111.6 MPa after 28 days. The strength development over time was significant for APM2, the increase in strength from 7 to 28 days was noted to be $39 \%, 51.4 \%$ and $42.7 \%$ for ambient, $30^{\circ} \mathrm{C}$ and $60^{\circ} \mathrm{C}$ curing temperatures respectively. Test results showed that $25 \%$ fly ash replacement with slag is the optimum percentage of the percentages examined in this study. APM3 samples $(\mathrm{F} / \mathrm{S}=50 / 50)$ were not significantly affected by curing temperature, with similar measured $\mathrm{f}_{\mathrm{j}}$ for all three curing conditions observed. This similarity in measured $\mathrm{f}^{\prime}{ }_{\mathrm{j}}$ is attributed to the presence of more slag content because calcium oxide present in slag hydrated faster and promoted early-age strength development even prior to heat curing application.

The compressive strength of APC cylinders $\left(\mathrm{f}^{\prime}{ }_{\mathrm{c}}\right)$ is much lower than that of APM cubes (see Figs $5 \mathrm{c}$ and 5d), which ranged between $6.3 \mathrm{MPa}$ and $7.8 \mathrm{MPa}$ after 7 days and between 6.5 MPa and $8.5 \mathrm{MPa}$ after 28 days. This is due to the presence of weak ECA aggregates, occupying $55 \%$ volume in the mixture. Nevertheless, APC specimens results followed a trend similar to that observed in APM cube testing results in terms of the relation to F/S proportion and curing temperature.

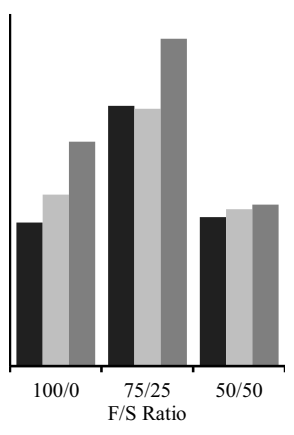

(a). APM-7 days

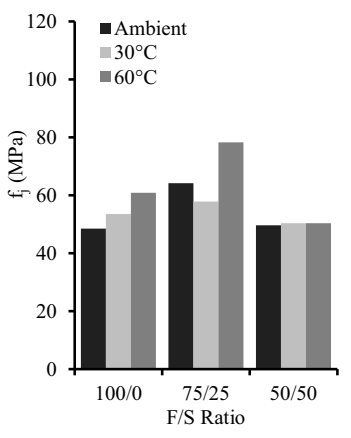

(b). APM- 28 days

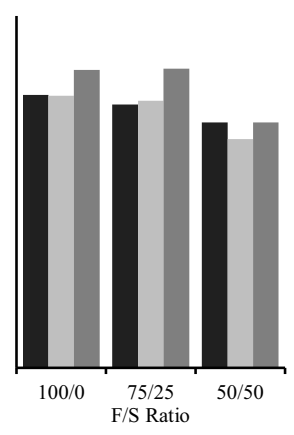

(c). APC- 7 days

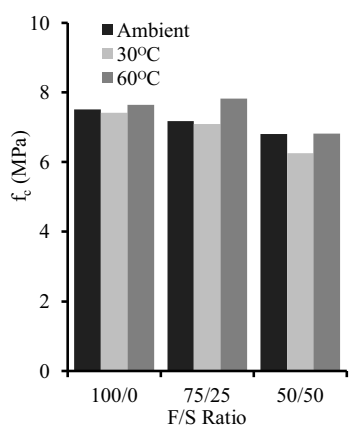

(d). APC- 28 days

Fig. 5. Compression strength test results. 
The compressive strength of ambient cured specimens of APC1 and APC2 had higher strength than their counterpart APC cylinders cured at $30^{\circ} \mathrm{C}$. This is because the ambient temperature reached up to $45^{\circ} \mathrm{C}$ during the testing duration. Similar strength was recorded for ambient and $60^{\circ} \mathrm{C}$ cured cylinders of APC3, whilst the strength dropped by approximately $8 \%$ for those cured at $30^{\circ} \mathrm{C}$.

\subsection{Tensile and flexural behaviour}

Experimental flexural strength $\left(f_{r}\right)$ and the split tensile strength $\left(f_{c t}\right)$ were calculated from recorded maximum applied loads and measured test specimen dimensions using Equations 1 and 2 respectively, where $F_{r}$ is maximum force from bending test, $F_{c t}$ is maximum applied splitting force, $\mathrm{b}$ is test prism width, $\mathrm{h}$ is test prism height, $\mathrm{d}$ is test cylinder diameter, and 1 is test specimen length. ACI 318 [15] propose Equation 3 and AS 3600 [16] propose Equation 4 to predict the APC tensile strength $\left(\mathrm{f}_{\mathrm{ct}}\right)$ from compression strength $\left(\mathrm{f}^{\prime}{ }_{\mathrm{c}}\right)$.

$$
\begin{aligned}
& f_{\mathrm{r}}=F_{\mathrm{r}} l / b h^{2} \\
& f_{\mathrm{r}}=2 F_{\mathrm{ct}} l / \pi d l \\
& f_{c t}=0.36\left(f^{\prime}\right)^{1 / 2} \\
& f_{c t}=0.56\left(f^{\prime}\right)^{1 / 2}
\end{aligned}
$$

It can be seen in Figures $6 a$ and $6 b$ that the $f_{r}$ slightly decreased with increasing slag content. Likewise, the splitting tensile strength reduced when $50 \%$ of fly ash was replaced but increased by $11.8 \%$ to $6.3 \%$ when $25 \%$ fly ash replaced by slag when compared to their counterpart fly ash only APC specimens. It was noted that the strength of some specimens cured at $30^{\circ} \mathrm{C}$ resulted in a higher strength than that of ambient cured specimens, which was possibly due to variation in material properties and/or production quality. Curing temperature of $60^{\circ} \mathrm{C}$ yielded the highest strength in all cases.

In Figure $6 \mathrm{c}$, a correlation between the compressive strength and the flexural/ tensile strength was noted. The flexural/tensile strength was found to be proportional to the measured compressive strength, with measured tensile strength lying in the middle zone between the values predicted using the two equations, but closer to the prediction made using the equation recommended by Australian concrete standards. This also suggested that the APC behaved differently than cement concrete and strength models developed for the latter may not be applied to APC.

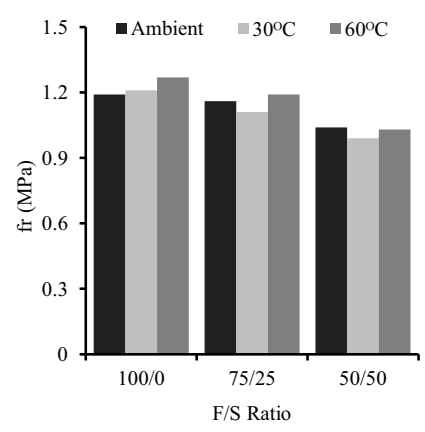

(a). Flexural strength

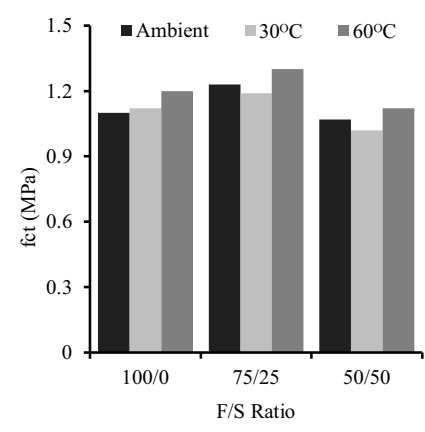

(b). Split tensile strength

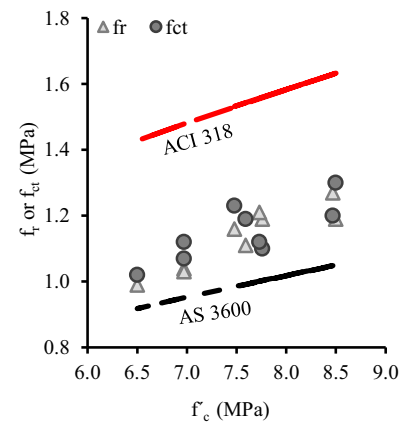

(c). Correlation with $\mathrm{f}^{\prime} \mathrm{c}$

Fig. 6. Flexural and tensile strength test results. 


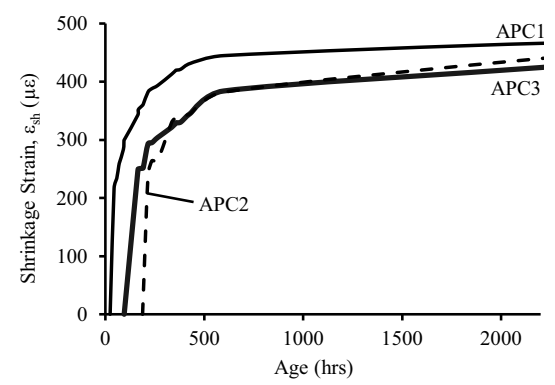

(a). Plastic shrinkage strains

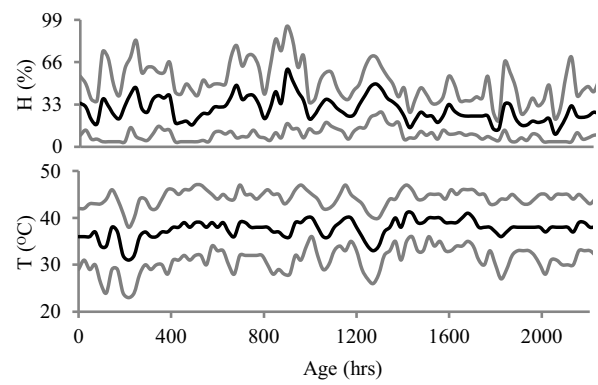

(b). Humidity $(\mathrm{H})$ and temperature $(\mathrm{T})$

Fig. 7. Shrinkage testing results.

\subsection{Plastic shrinkage strains}

The shrinkage strains, ambient temperature, and ambient relative humidity were monitored over a period of 2207 hours from mixing time. Figure 7a shows the shrinkage values versus time elapsed since mixing and Figure $7 \mathrm{~b}$ shows the recorded ambient temperature and relative humidity values. It was noted that the volume changed mainly in the first four days due to moisture movement from APC to the surrounding environment. This followed occurrence of shrinkage strains at a gradually reducing rate between 4 and 25 days, with these strain rates approaching zero after 25 days. Observed shrinkage trends of all mixtures were similar, however higher shrinkage strains were recorded in prisms produced using APC1 mixture. This indicated that plastic shrinkage strains reduced when fly ash was replaced with slag. This observation was similar to those reported in a previous study [17]. After 2207 hours since mixing, the shrinkage strain values reached 466,424 and 440 micro-strain $(\mu \varepsilon)$ for $\mathrm{APC} 1, \mathrm{APC} 2$ and APC3 respectively.

\section{Conclusions and recommendations}

The effects of fly ash replacement by slag and curing conditions on properties of fresh and hardened APM and APC were studied experimentally. The addition of slag reduced workability and setting time due to water consumed for hydration of free-lime present in slag. The compression strength of APM2/APC2 mixture was the highest, and high curing temperature promoted polymerization and, consequently, resulted in high strength. That makes $25 \%$ fly ash replacement by slag the optimum percentage among the examined. Also, slag addition to APC positively influenced plastic shrinkage by reducing the shrinkage strains. The measured APC strength was noted to directly relate with curing temperature, with $60^{\circ} \mathrm{C}$ curing temperature to result in the best mechanical properties. Ambient curing in UAE summer conditions had better or comparable results to those observed for specimens cured at $30^{\circ} \mathrm{C}$. The concrete strength was highly associated to quality of ECA, whilst used ECA with low tensile strength produced APC with low mechanical strength. Based on experimental results, further studies are recommended to be undertaken to optimise the APC mixture and/or to determine the effects of other variables, which can be used to develop realistic strength prediction/ behavioural models.

Financial support for this study was provided by the United Arab Emirates University under the grant 31N249. Assistance of Robin Debeer, Mohammed Al-Mawri, Muath Bassam, Abdalla ElHashmi, Faisal Ali, and Abdelrahman Sallamin are gratefully acknowledged. Ashtech International supplied fly ash. Emirates Cement Factory provided slag and assisted with x-ray fluorescence testing. 


\section{References}

1. Olivier JGJ, Maenhout GJ, Muntean M, and Peters J. Trends in global CO2 emissions: 2015 Report. Ispra, Italy: European Commission Joint Research Centre Institute for Environment and Sustainability; 77 (2015)

2. de-Vargas AS, Dal Molin DCC, Vilela ACF, da-Silva FJ, Pavao B, and Veit H. The effects of $\mathrm{Na} 2 \mathrm{O} / \mathrm{SiO} 2$ molar ratio, curing temperature and age on compressive strength, morphology and microstructure of alkali-activated fly ash-based geopolymers. Cement and Concrete Composites. 33(6), p. 653-60 (2011)

3. Hardjito D, Wallah SE, Sumajouw DMJ, and Rangan BV. On the development of fly ash-based geopolymer concrete. ACI Materials Journal. 101(6), 467-72 (2004)

4. Junaid MT, Kayali O, Khennane A, and Black J. A mix design procedure for low calcium alkali activated fly ash-based concretes. Construction and Building Materials 79, 301$310(2015)$

5. ASTM C136-14: Standard test method for sieve analysis of fine and coarse aggregates. West Conshohocken, PA: American Society for Testing and Materials International (2014)

6. ASTM C168-15: Standard specification for coal fly ash and raw or calcined natural pozzolan for use in concrete. West Conshohocken, PA: American Society for Testing and Materials International (2015)

7. ASTM C29-16: Standard test method for bulk density ("unit weight") and voids in aggregate. West Conshohocken, PA: American Society for Testing and Materials International (2016)

8. ASTM C191-13: Standard test methods for time of setting of hydraulic cement by Vicat needle. West Conshohocken, PA: American Society for Testing and Materials International (2013)

9. ASTM C143-15: Standard test method for slump of hydraulic-cement concrete. West Conshohocken, PA: American Society for Testing and Materials International (2015)

10. ASTM C109-16: Standard test method for compressive strength of hydraulic cement mortars (using $50 \mathrm{~mm}$ cube specimens). West Conshohocken, PA: American Society for Testing and Materials International (2016)

11. ASTM C39-15: Standard test method for compressive strength of cylindrical concrete specimens. West Conshohocken, PA: American Society for Testing and Materials International (2015)

12. ASTM C496-11: Standard test method for splitting tensile strength of cylindrical concrete specimens. West Conshohocken, PA: American Society for Testing and Materials International (2011)

13. ASTM C78-16: Standard test method for flexural strength of concrete (using simple beam with third-point loading). West Conshohocken, PA: American Society for Testing and Materials International (2016)

14. ASTM C490-11: Standard practice for use of apparatus for the determination of length change of hardened cement paste, mortar, and concrete. West Conshohocken, PA: American Society for Testing and Materials International (2011)

15. ACI 318-08: Building code requirements for structural concrete. Farmington Hills, MI: American Concrete Institute (2008)

16. AS 3600-09: Concrete structures. Sydney, NSW, Australia: Standards Australia International (2009)

17. Deb PS, Nath P, Sarker PK, Drying shrinkage of slag blended fly ash geopolymer concrete cured at room temperature, Procedia Engineering, 125, 594-600 (2015) 